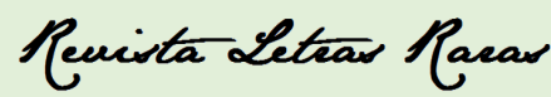

ISSN: 2317-2347 - Vol. 5, Ano 5, № 3 - 2016

\title{
Aula pública: catalogação de um gênero discursivo
}

Felipe Freitag*

Segundo Mikhail Bakhtin (1999), os gêneros do discurso dizem respeito ao emprego da língua sob a forma de enunciados (orais e escritos) relativamente regulares em uma concretude e/ou materialização única em esferas comunicativas específicas, na qual integrantes de uma dada comunidade de prática humana enunciam-se como seres partícipes de determinada realidade, enunciam-se a partir dessa determinada realidade e enunciam essa realidade.

Pode-se afirmar que os múltiplos campos de atividade humana produzem enunciados sui generis que, de algum modo, "traduzem" uma identidade social, histórica, cultural e ideológica por meio do uso contextual e particular da língua. Tais enunciados resultam em enunciações através da dialogicidade (interação dialogal entre interlocutores), a qual é entendida como o princípio fundante e fundamental da linguagem para Bakhtin. As enunciações são consequência do processo de construção de enunciados marcados por uma situação social e por condições específicas de constituição e, portanto, podem ser compreendidas como unidades da comunicação discursiva que se parametrizam produzindo gêneros discursivos.

Levando-se em conta que "o centro organizador de toda a enunciação, de toda a expressão não é interior mas exterior: está situado no meio social que envolve o indivíduo" (BAKHTIN, 1999, p. 118), os gêneros discursivos são produzidos em função das socioculturabilidades de sujeitos constituintes de um grupo humano específico, o qual é constituidor de uma realidade linguística que é, também, ideológica. Todo gênero discursivo apresenta um tema, um estilo e uma composição, as quais refletem características ímpares e distintivas do uso linguístico de dada comunidade de prática humana e, por consequência, da própria comunidade de prática humana.

O tema é a expressão de um conteúdo ideológico subjacente à comunidade de prática humana que elabora um gênero discursivo x, sendo um assunto de interesse dos e os sentidos expressos intencionalmente pelo compósito humano daquela. O estilo é o modo de realização da língua, ou seja, é o como os sujeitos de dada comunidade de prática humana “dizem-se" e

\footnotetext{
* Autor. Licenciado em Letras Português pela Universidade Federal de Santa Maria. Mestre em Estudos Linguísticos pela Universidade Federal de Santa Maria. Educador linguoliterário. Revisor linguístico instrucional no Núcleo de Tecnologia Educacional da Universidade Federal de Santa Maria. E-mail: feletras2007@hotmail.com.
} 


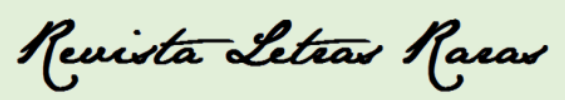

ISSN: 2317-2347 - Vol. 5, Ano 5, № 3 - 2016

Bakhtin afirma os gêneros discursivos partem de lugares sociais, ou esferas sociais definidas e, por essa razão, sua produção não se alicerça em um vácuo social, mas sim se organiza de acordo com as relações de ocupação dessas esferas por membros humanos que as caracterizam, que as expressam e que as consolidam pelo uso da linguagem. As esferas sociais do cotidiano (grupos que comungam vidas e experiências intimamente, como, por exemplo, uma família) originam o que Bakhtin chama de gêneros primários, os quais dizem respeito à situações comunicativas do cotidiano (normalmente na fala), entendidas como informais e de realização imediata (espontânea, de elaboração menos complexa). As esferas sociais de sistemas ideológicos já constituídos (arte, ciência, religião, política, imprensa, ciência, etc) originam o que Bakhtin chama de gêneros secundários, os quais dizem respeito à situações comunicativas mediadas, sobremaneira, pela escrita, de caráter formal e de realização menos imediata (não espontânea, de elaboração mais complexa). Os gêneros secundários são formados a partir da reelaboração de gêneros primários, assim:

\begin{abstract}
Os gêneros discursivos secundários (complexos - romances, dramas, pesquisas científicas de toda espécie, os grandes gêneros publicísticos, etc.) surgem nas condições de um convívio cultural mais complexo e relativamente muito desenvolvido e organizado (predominantemente o escrito) - artístico, científico, sociopolítico, etc. No processo de sua formação eles incorporam e reelaboram diversos gêneros primários ( simples), que se formaram nas condições da comunicação discursiva imediata. Esses gêneros primários, que integram os complexos, aí se transformam e adquirem um caráter especial: perdem o vínculo imediato com a realidade concreta e os enunciados alheios: por exemplo, a réplica do diálogo cotidiano ou da carta no romance, ao manterem a sua forma e o significado cotidiano apenas no plano do conteúdo romanesco, integram a realidade concreta apenas através do conjunto do romance, ou seja, como acontecimento artístico-literário e não da vida cotidiana. No seu conjunto o romance é um enunciado, como a réplica do diálogo cotidiano ou uma carta privada (ele tem a mesma natureza dessas duas), mas à diferença deles é um enunciado secundário (complexo) (BAKHTIN, 2003, p. 263).
\end{abstract}

Diante da constatação da existência de uma forma discursiva mais, ou menos estável em composição e em temática, enquanto fenômeno social, histórico, cultural e ideológico realizado em um contexto de oralidade e da posterior verificação da sua não catalogação científica, propõe-se, nesse texto, registrar a aula pública como um gênero discursivo. ${ }^{1}$ A seguir, arrolam-

$1 \quad$ O autor desse texto verificou tal existência ao longo de sua trajetória de vida e de sua trajetória acadêmica ao longo dos últimos oito anos na cidade de Santa Maria, RS. A aula pública é muito comum na cidade em questão e é utilizada, sobretudo, por movimentos sociais que lutam por direitos humanos, como, por exemplo, movimento feminista, movimento LGBTT, movimento negro, etc. para discutir publicamente (em espaços que se pretendem populares e de fácil acesso) assuntos de pouco visibilidade em termos de abrangência e de caráter urgente (porque atuais e ligados a fatos circunstâncias do cotidiano, como, por exemplo, o machismo, a homofobia, o racismo). 


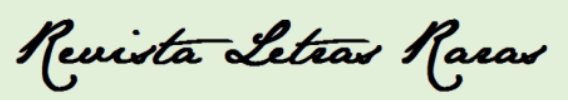

ISSN: 2317-2347 - Vol. 5, Ano 5, № 3 - 2016

se algumas evidências reais da existência do gênero discursivo aula pública como acontecimento sociodiscursivo:“dizem” sua ideologia através da maneira mais representativa (mais próxima do real) do sociocultural e histórico que os caracteriza e define. A composição é a estruturação e/ou organização da língua sob a forma de enunciados, isto é, é o arranjo formal da língua escolhido para melhor veiculação e representação do tema e do estilo de dado gênero discursivo de dada comunidade de prática humana.

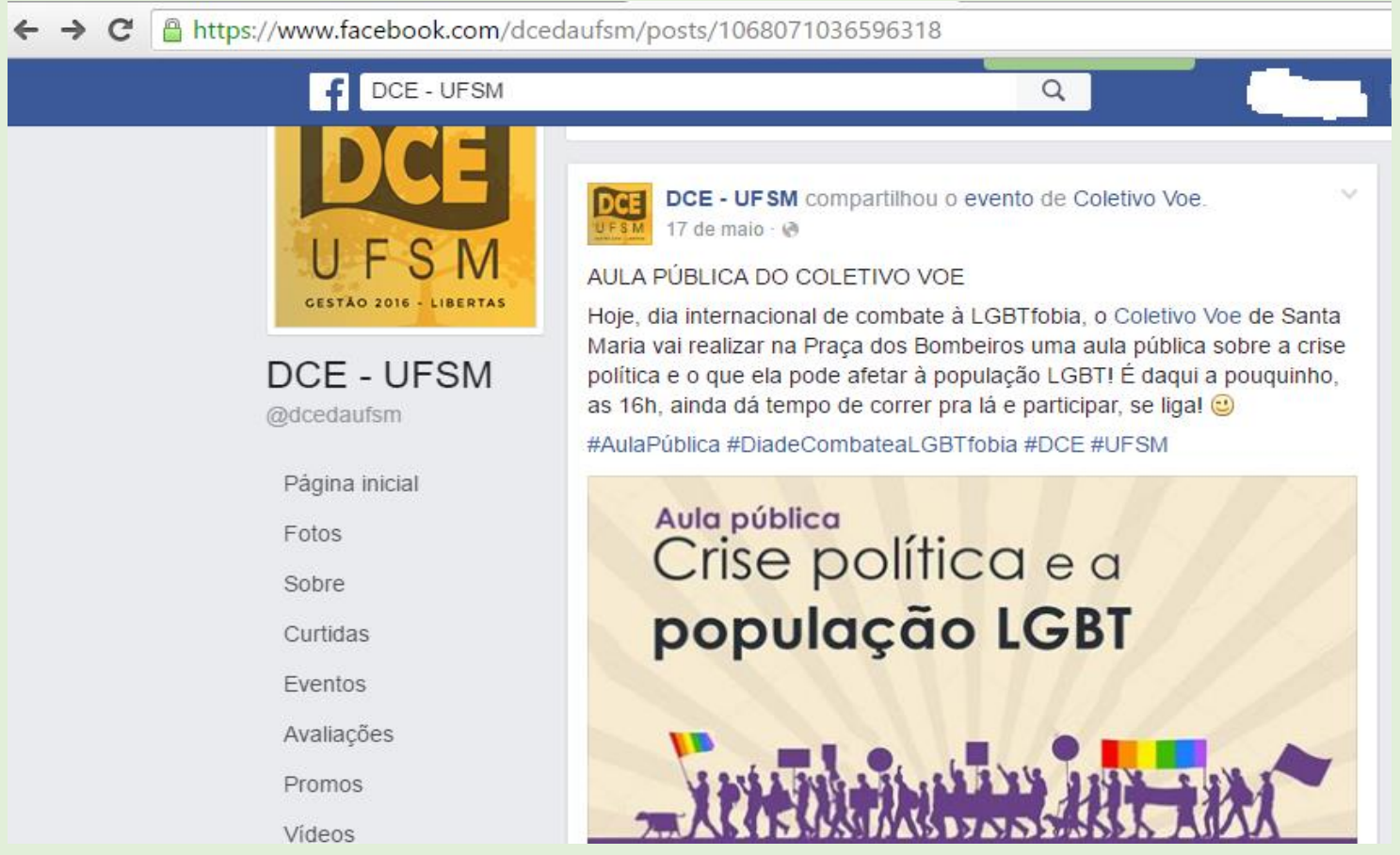

Figura 1: Chamada para Aula pública-Coletivo Voe.

Autor: Fanpage -Facebook-DCE UFSM (2015). 


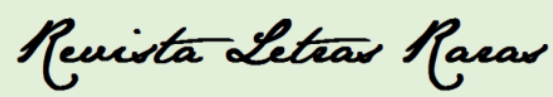

ISSN: 2317-2347 - Vol. 5, Ano 5, № 3 - 2016

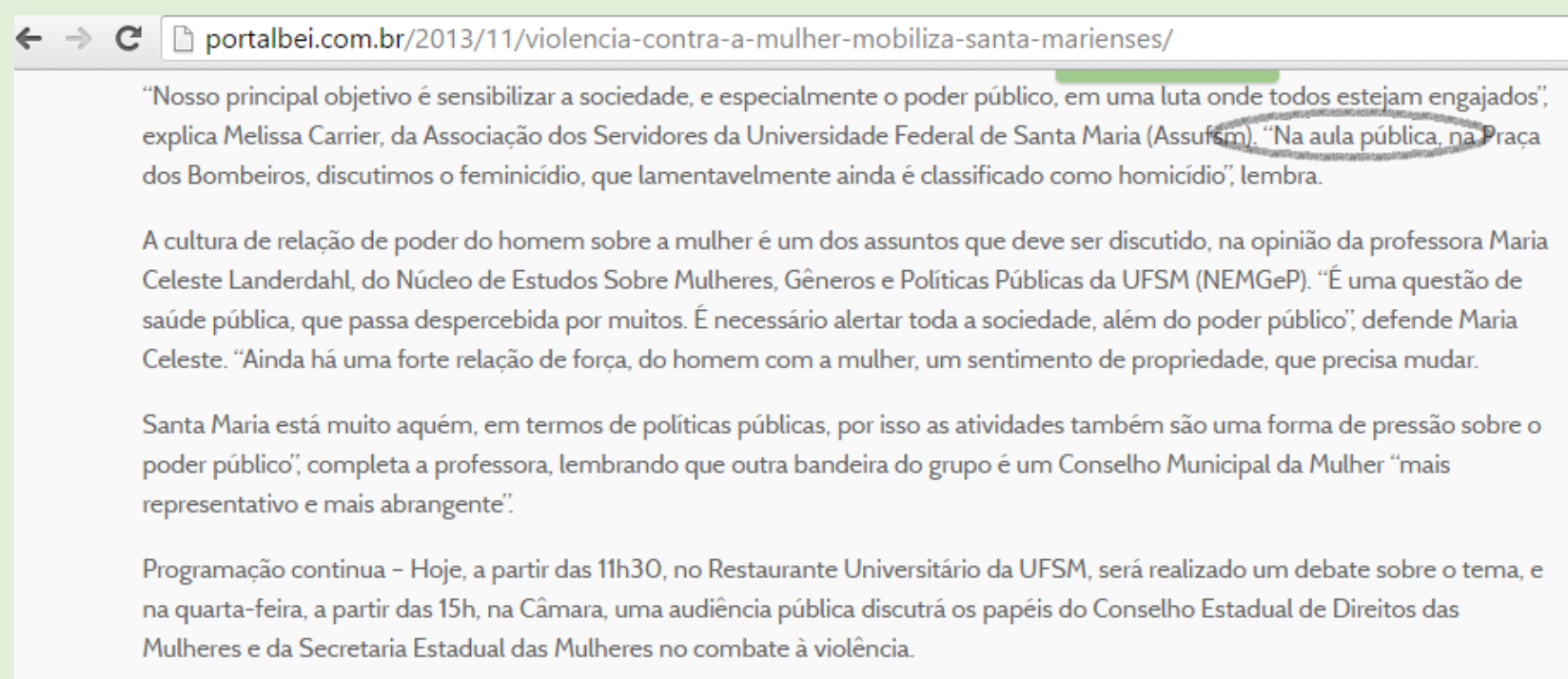

Figura 2: Trecho de fala sobre Aula pública-NEMGeP-UFSM.

Autor: Portal Bei (2015).

Evidenciada tal existência do gênero discursivo aula pública no seio sociocultural e histórico do século XXI (as figuras 1 e 2) e, não encontrando nenhuma referência teóricoconceitual sobre ele em bibliografias da área de Linguística, tentar-se-á, mesmo que primariamente, sistematizá-lo como gênero discursivo oral a partir da participação (ouvinte) do autor desse texto em algumas aulas públicas ocorridas em Santa Maria, RS, nos últimos anos. Definimos o gênero discursivo aula pública como aquele que está próximo do debate oral regrado, pois sua realização é oralizada (canal físico) e pretende discutir argumentativamente algum assunto de grande premência social, tendo com fins a informação e a persuasão. Tanto o debate oral quanto a aula pública apresentam uma temática que se desmembra em subtemas a partir do tema central, sobretudo pela fluidez argumentativa proporcionada pela oralidade (em um debate entre candidatos a um dado governo, dentro da temática Política, os adversários lançam subtemas, como, por exemplo, Educação, Economia, etc.). Entretanto, tal fluidez é muito maior no gênero aula pública, uma vez que os espectadores (audiência, público) são participantes ativos do e no processo de discussão de dado assunto (o que não acontece no debate oral regrado, em que apenas os participantes têm direito à fala).

Mas, nesse caso, o que diferencia a aula pública de um debate? Qual é a característica que dá ao gênero o título de "aula"? 


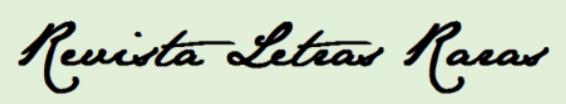

ISSN: 2317-2347 - Vol. 5, Ano 5, № 3 - 2016

1) Formação: Em uma aula pública, a persuasão do público não é tão "inquiridor" quanto em um debate oral regrado, já que o status, ou o ethos de aula dá ao gênero discursivo em questão um caráter de formação e não de informação apenas. Formação no sentido de co-construção (palestrantes e espectadores) do conhecimento sobre dada temática. Em um debate oral regrado, por exemplo, o papel interlocucional é entre debatedor e debatedor, os quais digladiam forças (argumentativo-ideológicas) com o fito de convencer o público e não de formá-lo critica e reflexivamente.

2) Espaço: Uma aula pública pretende-se realizável em espaço público e informal, como, por exemplo, uma rua, uma praça, uma calçada, dentro de uma noção de ocupação de espaços públicos para a gestão democrática (socioparticipativas) dos mesmos.

3) Espectadores e Palestrantes: Os palestrantes são sujeitos com alguma representação real de especialista no concernente ao tema abordado em dada aula pública. Eles são só responsáveis por trazer os subsídios primários ao debate (conceitualizar e problematizar de modo a inserir os espectadores na discussão). Os espectadores de uma aula pública, também, têm direito à fala (solicitam a fala em um papel-ficha e cada um tem o mesmo tempo de fala para argumentar com os palestrantes e/ou com os outros espectadores). Existe, então, um jogo de construção democrática e dialético do conhecimento (palestrantes e palestrantes; palestrantes e espetadores; espectadores e palestrantes; espectadores e espectadores). Em uma aula pública, chama-se de inscrição essa solicitação de fala dos espectadores em um papel-ficha.

4) Linguagem: Em uma aula pública, procura-se pelo uso linguístico (fala, oralização) que mescle informalidade e formalidade. Essa mescla advém, sobretudo, da discussão de conceitos por meio de uma linguagem didatizada (informal, simplificada, problematizadora) e dialógica (que dê aberturas para os espectadores contra argumentarem, concordando, discordando, complementando, etc.). Também, faz-se sempre necessário verificar visualmente quem é o público presente na aula público, pois assim, se pode aumentar, ou diminuir o nível de complexidade linguística utilizada nas falas.

Em suma, acredita-se serem esses os quatro pontos diferenciadores do gênero discursivo aula pública e, em consequência, o que o torna singular a ponto de ser classificado como um gênero do discurso a partir da noção bakhtineana de mesmo nome. Pode-se afirmar que uma aula pública é uma espécie de aula sem o "cárcere" da universidade, da escola, etc. e da 


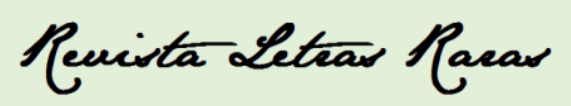

ISSN: 2317-2347 - Vol. 5, Ano 5, № 3 - 2016

"autoridade" de uma pessoa como a única detentora do conhecimento. Abaixo, ilustra-se a tripartição organizacional do gênero discursivo aula pública:

\begin{tabular}{|c|c|}
\hline Gênero discursivo aula pública & \\
\hline Tema & $\begin{array}{l}\text { De grande apelo social (premência de ser discutido em } \\
\text { face de acontecimentos atuais envolvendo assuntos de } \\
\text { urgente discussão). Ideologia baseada no protagonismo } \\
\text { (mulheres discutindo sobre agressão contra mulheres; } \\
\text { LGBTTs discutindo sobre homo-lesbo-bi-transfobia). } \\
\text { Ex: discussão sobre violência contra a mulher depois } \\
\text { que o Brasil presencia um caso de estupro coletivo } \\
\text { envolvendo uma adolescente menor de idade em } 2016\end{array}$ \\
\hline Estilo & $\begin{array}{l}\text { Uso informal, problematizador e dialético da língua por } \\
\text { meio da oralização. Formação dialógica (exposição, } \\
\text { argumentação, contra argumentação, reflexão). Gestão } \\
\text { democrática da discussão do assunto (palestrantes e } \\
\text { espectadores em graus próximos de hierarquia de lugar } \\
\text { de fala). Dizer-se e a partir das experiências de vida. } \\
\text { Refletir sobre assuntos atuais. Construir uma ligação } \\
\text { entre o conceitual e o informal através da ocupação de } \\
\text { espaços públicos (acesso à informação) e da linguagem } \\
\text { (didatismo). Levar à população como um todo, } \\
\text { informações restritas (de pouca visibilidade) através de } \\
\text { uma aula em espaço público, a qual se pretende não } \\
\text { dogmática, mas sim, elucidativa e reflexivo-crítica. }\end{array}$ \\
\hline Composição & $\begin{array}{l}\text { Falas de palestrantes sobre um assunto x. Falas dos } \\
\text { espectadores sobre um assunto x. Reflexão sobre as } \\
\text { falas. Co-construção do conhecimento através da } \\
\text { democracia da distribuição das falas. Registro oral. } \\
\text { Argumentos orais. Realização em espaços públicos } \\
\text { (ruas, praças, pátios, etc.). Papel-ficha (inscrições de } \\
\text { fala como organização democrática das falas dos } \\
\text { espectadores). Espaço formativo em que a persuasão se } \\
\text { dá pelo ato de expor, de argumentar, de contra } \\
\text { argumentar e de refletir. }\end{array}$ \\
\hline
\end{tabular}




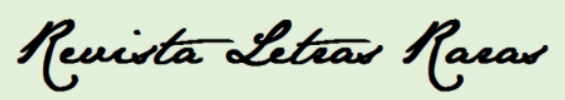

ISSN: 2317-2347 - Vol. 5, Ano 5, № 3 - 2016

Procurou-se, ao longo desse texto, apresentar a aula pública com o objetivo de propor sua catalogação como gênero discursivo oral na perspectiva teórica bakhtineana (não se encontrou nenhum material teórico acerca da aula pública), trazendo a tona os seus primeiros índices de descrição e de classificação. Não se intentou esgotar a reflexão sobre o assunto, mas sim se procurou indicar caminhos para pesquisas futuras sobre ele.

Em resumo, procurou-se estabelecer uma configuração conceitual preliminar acerca do fato social e discursivo (existência da aula pública no âmbito sociocultural) que tem ganhado força nas sociovivências do século XXI (principalmente em movimentos sociais relacionados a direitos humanos) como instrumento para fomentar debates democráticos, em espaços públicos, sobre assuntos atuais e negligenciados/tangenciados, de maneira a possibilitar uma formação que não se restrinja a ambientes de menor acesso para a maioria da população (universidades, por exemplo) e que se paute pelo didatismo da e na linguagem (informalidade, problematização, dialética igualitária, exposição, argumentação, reflexão).

\section{Referências bibliográficas:}

BAKHTIN, Mikhail. Marxismo e filosofia da linguagem. São Paulo: Hucitec. 1999.

BAKHTIN, Mikhail. Estética da criação verbal. São Paulo: Martins Fontes, 2003.

FACEBOOK.Figura1.Disponívelem:<https://www.facebook.com/dcedaufsm/posts/10680710 36596318>. Acesso em: 01 jul. 2015.

PORTAL BEI. Figura 2. Disponível em:<http://portalbei.com.br/2013/11/violencia-contra-amulher-mobiliza-santa-marienses/>. Acesso em: 01 jul. 2015.

Recebido em: 14/07/2016

Aceito em: 30/10/2016 